\title{
Monitoring the technological processes in the wood industry in order to make them more efficient through technical overhauling
}

\author{
Radu Dan Paltan ${ }^{1}$, Cristina Biriș ${ }^{2}$, and Loredana Anne-Marie Rădulescu ${ }^{1}$ \\ ${ }^{1}$ Transilvania University of Brașov, B-dul Eroilor nr.29, 500036 Brașov, Romania \\ ${ }^{2}$ Department of Industrial Machines and Equipments, Lucian Blaga University of Sibiu, B-dul \\ Victoriei 10, Sibiu, Romania
}

\begin{abstract}
Of many techniques that are used to optimize production and costs, the studies conducted within a profile company lead to our choice for testing the 6Sigma method (the most used method in the automotive industry) in view of the economic efficiency applied in the wood Industry company. This method measures how many flaws exist in a process and determines in a systematic way how to improve it by technical overhauling and eliminating or minimizing the process for efficiency. This research article aims to study the state of research on the optimization of the production process through technical overhauling for panels reconstituted from solid wood and ways to make production more efficient by cutting costs through technical overhauling. From preliminary research, we estimate that all the items founded and others that will result from further research will result in a significant decrease in production costs that are reflected in the cost of the finished product and consequently in increasing the yield of the company by maximizing its profit. At the same time it may be the basis of future research studies in the field. The easier it is to maximize profits, the lower the operating costs are and the higher recovery rate of investments are, that will result a change in the operating mode: "working smarter not harder".
\end{abstract}

\section{Introduction}

The purpose of any company and, implicitly, those in the wood industry is to obtain the maximum profit. For this, special attention should be paid by the management to finding the adequate method of optimizing the production flow, maintaining or even increasing the quality and finishing of finished products by processing operations and methods that are the easiest to be implemented and at the same time giving the fastest and most significant results from a quantitative and qualitative point of view.

\footnotetext{
* Corresponding author: cristina.biris@ulbsibiu.ro
} 
Machining operations of solid wood are optimized with the aim of reducing energy, time and technological consumption of raw materials in a process. The methods are technically dependent and have a direct effect on the quality of the product.[1,7,10,13]

The optimization of a technological process implies first of all the correct evaluation of all the factors and their ranking according to the influence on the analysed process, as well as the consideration of the interaction between them (see Figure 1).

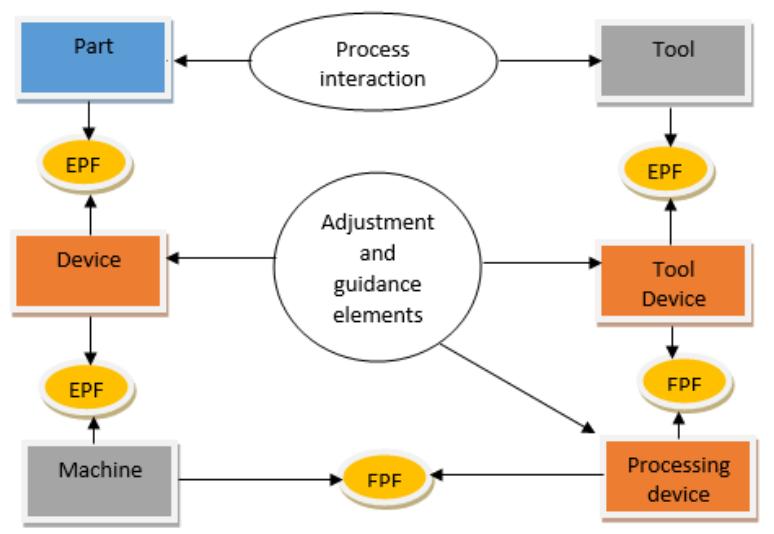

Fig. 1. Scheme of the functional interdependence and links between different components of the technological system [1].

\section{Clasification and methods}

Classification of optimization methods is a problem with a high degree of subjectivity, given the large variety and complexity of both the purpose functions and the restrictions that may occur in optimization problems. However, this wide variety of methods is grouped into four classes:

- Exhaustive enumeration method;

- Classic optimization methods;

- Numerical or direct search methods (climbing the hill);

- Programming methods.[2]

The exhaustive enumeration method is rarely chosen and consists of calculating the value of the target function for a large number of decision vector values $p_{x}$ in such a way as to ensure that it has not passed the maximum or minimum sought. The values calculated for the purpose function are compared to each other until the maximum or minimum value is reached

The classical optimization method can only be applied to defined, continuous, and derivable goals. The problem is getting complicated if the decision variables are linked by equality or inequality restrictions. The greater the number of decision variables and restrictions are, the more difficult the problem is.

Numerical or direct search methods or "hill climbing". These methods are a sort of planned numerical experiments, which evolve step by step through successive improvements to the targeted extremities. This category of methods can be compared with the way in which the mountain peak is escalated for the first time. Numerical methods are also applicable to find the optimal way, without having a model, through experimental methods.

Programming methods are high-efficiency methods that represent the main content of advanced techniques in the optimization domain. Each type of programming method is specific to 
a particular type of optimization problem. The most common types are the following types of programming methods:

-Linear Programming - A particularly common algorithm used to solve linear programming problems is the simplex algorithm developed by George DANTZIG;

- Dynamic programming;

- Quadratic programming;

- Geometric programming. [12]

\section{Research methodology}

The scientific literature recommends optimizing processes based on various optimization criteria depending on the nature of the studied process. There are three large groups of criteria dedicated to optimization (Figure 2):

- technical criteria (productivity, quality, consumption, etc.);

- economic criteria (profit, return on investment, added value of the product, etc.);

- ecological criteria (dust, noise, VOC, formal dehyde, etc.). [3,11]

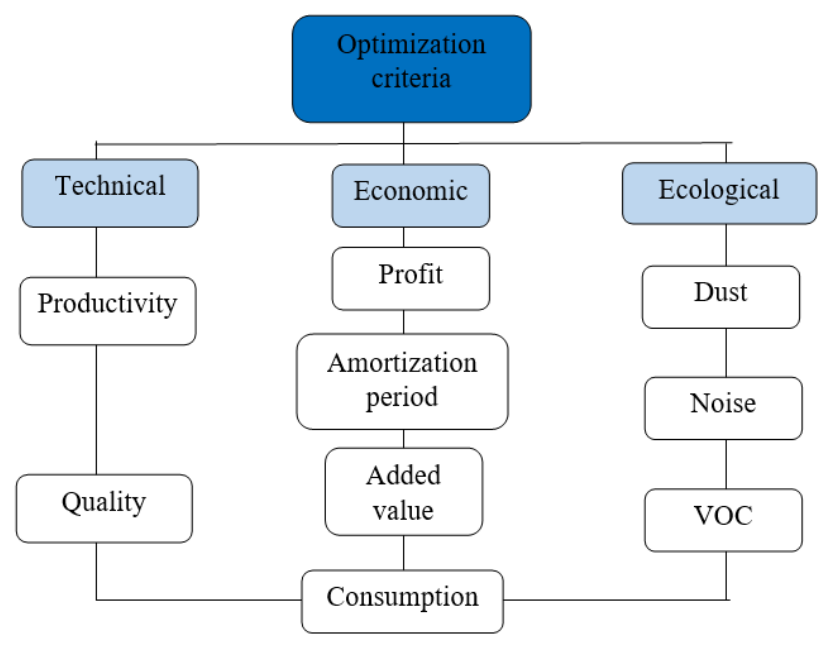

Fig. 2. Classification of optimization criteria.

In economic terms, the optimization method shows the action of choosing and applying the optimal (economic) solution (among many possible).

In mathematical terms, optimization presents the reasoning or calculation that allows you to find the values of one or more parameters corresponding to the maximum of a function.

\subsection{The optimizing processes}

In general, solid wood machining operations are economically optimized by modelling in the initial version and subsequently by technical methods applied in the technological process in order to reduce energy, time and technological consumption, raw materials etc., and which are quantified in monetary value.

MODELING a technological process means the transformation, its processing, the creation of a tangible model, simulation or mathematical model (in most cases, by mathematical transposition). [4,9] 
PROCESS - Following the modelling of technological processes, the specialist can optimize working regimes, geometric parameters of tools, machine tools characteristics etc. by developing optimization processes that take into account the requirements, possibilities, technical performances.

Solving a problem of programming an optimized process involves firstly the correct assessment of all the factors that may influence the process under consideration, as well as the consideration of the interaction between them. In order to achieve the desired goal, a model needs to be built for the studied process. In the broad sense of the word, the model is a construction that behaves like the process or system it represents. The mode of expression of the model is very diverse depending on the purpose pursued starting with:

- tangible representation such as analog electrical circuits; small scale pilot units, test stands;

- simulations such as computer programs, logical relationships and so on and ending with pure abstract representation such as mathematical relationships.

As mentioned above, the scientific literature for the wood industry uses various optimization criteria to optimize the processes according to the nature of the studied process. The most general and all-encompassing are: technical, economic and ecological.[5,14]

\subsubsection{The technical criteria}

Categories of technical criteria include:

a. The productivity criteria to be maximized. This generally refers to working capacity related to runtime. In particular, it refers to working capacity related to execution time. These criteria can be satisfied if management pays constant and continuous attention to the manufacturing process for products through constant research and application of a model based on standard techniques where it can be realized and the results can be implemented in the production stream in order to improve the system management and to increase the performance of processes and product quality.[6]

Performing modelling focused on standard techniques involves the use of a set of classical algorithms determined for that model.

From the category of standard (classic) optimization techniques we have:

- direct Search Methods (MCD) - Focused on techniques that do not use the function derivation of the function $\mathrm{F}(\mathrm{x})$;

- gradient methods (MG) - which use the calculation of the derivatives of the order "1" or possibly "2" of the function $\mathrm{F}(\mathrm{x})$;

- transformation methods - these translate the original problem into one, or a set of equivalent, easier-to-solve (typically dualistic, or penalty / partitioning) sub-problems.

b. The quality criteria to be maximized by introducing and applying the highest technical performance in the field.

Optimized parameters based on this criteria need to be maximized within a PROCESS.

Woodworking requires several operations that take place in a production process model to reach the massive wood panels. These can be determined by functions that measure accurate measurement.

For example, from a theoretical point of view, the purpose function can be considered in the case of woodworking for the milling step $\mathrm{H}_{\max }=\mathrm{uz} 2 / 8 \mathrm{R}$ considering $\left(\mathrm{u}_{\mathrm{z}}\right)$ the distance between two grains and $(\mathrm{R})$ the radius of the grinding cylinder. The quality of processed wood panels is characterized by geometric shape, dimensional precision and finishing. 


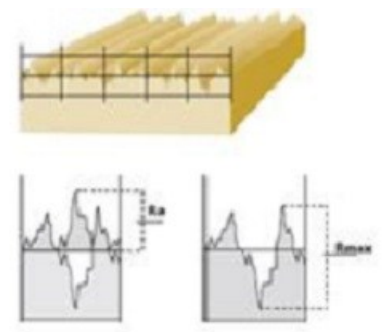

a.

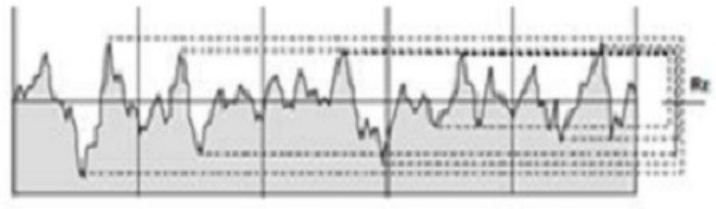

b.

Fig. 3. Geometry of the quality criteria of polished surfaces.

The following parameters were determined by experimental researches that determine the strength, concentration of dust and roughness according to the established methodology performed by Badescu, L.A.M., Rădulescu in the Modeling of Wood Chipping and Cutting Tools, 2016. Ed. Of Transilvania University, Braşov. [8]

Whatever the adopted optimization criteria is, its mathematical expression depends on the variables of the system. These can be:

- Decision variables of the system in question, those variables we give different values until the maximum or minimum value of the criterion is found.

- State variables that do not appear in function because they are not independent variables, but depend on system decision variables.

c. The consumption criterion. It is an ambivalent criterion. It must be minimized by adopting advanced technically solutions and maximized by optimizing those technological parameters that directly or indirectly lead to the reduction of consumption and which have a quantified effect in terms of economic effects in the production process.

A higher quality level can be achieved by eliminating as much as possible the elements that negatively influence the consumption of raw materials, materials and energy and will conclude by arguing the managerial decision to re-technologise the production lines and ultimately to maintain or increase the quality products

There are several operations in the production of solid wood panels. These include operations such as: cutting timber, drying, cutting wood lamella, forming the lamella mat, panel formwork, calibration and grinding.

Reducing consumption at these stages in addition to the technical aspect (wood / raw material reduction, material consumption, energy, emissions etc.) have an economic and ecological impact on the production activity, so that the resulting economies are quantified in monetary units and leading to cost savings, maximizing profit.

Example: increasing the amount of cut wood by increasing the speed of the saw blade is determined by several factors. So, increasing the speed of the saw blade:

- Increases the number of cutting elements that come in contact with the wood in the time unit.

- Decreases the tendency of grains to circumvent the hard areas of the wood rings, the wood being evenly sanded over the entire contact surface with the abrasive tape.

- At values above $20 \mathrm{~m} / \mathrm{s}$, the growth rate of grinding productivity decreases as unwanted phenomena (belt vibration, heating etc.) occur.

- The specific sanding $(\mathrm{K})$ decreases by increasing the grinding speed to a minimum of 20-25 m/ $\mathrm{s}$, then rises again.

- The productivity for $30 \mathrm{~m} / \mathrm{s}$ is higher in the beginning but then decreases sensibly, so after 3 hours it drops below the speed curve of $23 \mathrm{~m} / \mathrm{s}$ due to increased band vibration and its temperature. 
- The productivity for $23 \mathrm{~m} / \mathrm{s}$ grinding speed drops sharply in the first hour, after which it is almost constant, but after three hours of work it is superior to the speed of $30 \mathrm{~m} / \mathrm{s}$.

- The productivity of the grinding speed for $15 \mathrm{~m} / \mathrm{s}$ is small compared to the other two above.

- The average roughness values of dry and wet surfaces do not depend on the grinding speed, because the favorable grinding effect at high wheel speeds is diminished by the increase in belt vibrations.

- Increasing polishing speed increases the uniformity of polished surface quality.

- High grinding speeds determine superior quality

\subsubsection{Economic criteria}

For the study of socio-economic phenomena, various and often sophisticated research tools are required.

In order to take justified decisions on the basis of such indicators, the Operational Research Committee of the National Research Council of the United Kingdom recommends that the operational research should be in all its complexity and especially the connections and interdependencies that characterize the complex phenomenon. These are also the recommended steps for applying Scientific Methods for Analyzing and Solving Managerial Decision

The main features are:

- focusing primarily on the decision-making process;

- scientific substantiation of managerial decisions;

- examining decision situations from a comprehensive perspective;

- using methods and knowledge from many disciplines; creating a support for mathematical models;

-allows quantification of results and their analysis in digital/cybernetic form.

The particularities that generate the operational research activity concern the very complex methodological decision-making strategy. The operational research can respond to a wide range of problems of the economic practice: the operative and perspective planning, the optimal investment distribution, the duration of the investment recovery, the technical progress prognosis, analyzing the possibilities of increasing the added value of the manufactured products, increasing the economic profit, etc.

From the specialty literature it can be concluded that the development of an operational research has to go through six stages, as follows: Problem formulation, Design of a mathematical model, Determination of an optimal solution, Model and solution testing, Control and suitability of the solution, Transposition of the solution into practice.

\subsubsection{Ecological criteria}

The development and application of ecotechnology in industry and the services sector is a key requirement. The quality of ecotechnology knowledge depends on the efficiency of the multidisciplinary synthesis of knowledge and skills in natural sciences and technologies, information and communication sciences, economics, legal and social sciences. According to the ecological definitions and criteria, their application in the polishing process of the wood industry is of major interest. Woodworking impedes the environment by various factors.

These factors can be defined as ecological factors with direct impact on the cost of the finished product. These are: energy consumption, maximum utilization of raw materials, consumption of raw materials and materials, emissions of dust and dust, etc.

For example, polishing influences the environment through high energy consumption, dust release, noise emissions etc., which can be considered as factors influencing the anthropogenic 
system and consequently can be treated on the basis of ecological principles to contribute to sustainable development.

\section{Conclusions}

The importance of this research results from the importance of this topic, given that the furniture industry in Romania can represent a real vehicle for the national economy and a viable solution to the problem of irrational or defective exploitation of wood and unjustified gross wood export. It is possible to conclude for an export of pauperity in the case of Romanian wood, and by low or no processing the wood, it brings possibility of cargo valences, by offering the opportunity to bring added value to the foreign companies. Also, no regard if we relate to the internal or international competitive environment, the common reference to all economic systems is a permanent desire to increase competitiveness.

All these incrementing of the efficiency through minimization of the technological consumptions and the maximum utilization of the residual material in the wood industry are impetuously needed. That's because this industry is based on the raw material that is wood, an increasingly rare natural product and also on the attention to the environment as well as towards ecological emission technology and minimum pollution needs to be implemented through continuous technical overhauling to minimize impact on the environment. That's why from this study we have the fallowing conclusions:

1. The quality and cost of wood products and other finished wood products is a crucial condition in selling them on the market, attracting buyers, satisfying their desires and exigencies.

2. As a result of the above, we find that the current state of knowledge in the field of mechanical woodworking has reached a very high level in terms of: technology, machine tool and tooling system, optimization solutions of the processing process on various criteria technical. There are information databases on technical research and inventions in the field of wood processing technology and wood-based products.

3. However, both the quality and the cost of wooden products and other finished wood products must be taken into account, as this are the decisive conditions for their marketing, attracting the buyers, satisfying the clients wishes and requirements.

4. In the scientific researches carried out in this article on the management part with application in the wood processing, it was concluded that researches of this type are relatively low / or probably less popular, especially in our country or abroad (books and article found).

5. The quality and value of the products depends greatly on the performance of the machinery, the level of technical equipment, the organization of the manufacturing and processing processes.

From preliminary research, we estimate that all the items listed above and others that will result from both experimental and theoretical research will result significant production cost decreases, that are reflected in the cost of the finished product and consequently in increasing the yield of the producing company by maximizing their profit realized by this and at the same time it can be the basis of future research studies in the field.

\section{References}

1. R.D. Păltan, L.A.M. Rădulescu, Creativity and Innovation J., 9 (2016)

2. R.D. Păltan, C. Biriș, L.A. Rădulescu, MATEC Web of Conferences, 121, 02009 (2017)

3. R.D. Păltan, L.A.M. Rădulescu, C. Biris, PRO LIGNO, 13, 637 (2017)

4. R.D. Păltan, L.A.M. Rădulescu, C. Biris, AGIR Buletin, 4, 160 (2017)

5. C. Bailliencourt, s.a, Conception des dispositifs de captage sur machine a bois (Paris, INRS, 2018) 
6. R.L. Ackoff, C. W. Churchman, Fundamentals of operations research (New York, John Wiley and Sons, 1968)

7. C. Girjob, G. Racz, MATEC Web of Conferences, 121, 03008 (2017)

8. E. Lehmann, N.J. Fröhlich, J. Aerosol Sci., 19, 1433 (1998)

9. L.A.M. Rădulescu, Modeling of wood chipping and cutting tools (Ed. Univ Transilvania, Brașov, 2016)

10. C. Coșereanu, Furniture technology- Technological structure (Ed. Univ. Transilvania, Braşov, 2013)

11. I. Darii, Contributions to the optimization of the wood and wood-based composites based on ecological principles (Doctoral thesis, Brașov, 2011)

12. G. B. Dantzig, A. Orden, Ph. Wolfe, Pacific J. Math., 5, 183 (1955)

13. M.L. Lobonț, V. Zerbes, Techniques and tools for quality improvement, (Ed. Univ. Lucian Blaga, Sibiu, 2014)

14. W.J. Mitsch, S.E. Jorgensen, Ecological Engineering: An Introduction to Ecotechnology (New York, John Wiley \& Sons, Inc., 1989) 